\title{
Global Health
}

\author{
Series Editor: Gustavo Matute-Bello, M.D.
}

\section{The Lung Corps' Approach to Reducing Health Disparities in Respiratory Disease}

\author{
Neeta Thakur ${ }^{1 \star}$, Meghan E. McGarry ${ }^{2 \star}$, Sam S. Oh ${ }^{1,3}$, Joshua M. Galanter ${ }^{1,3}$, Patricia W. Finn ${ }^{4}$, and \\ Esteban G. Burchard ${ }^{1,3}$; on behalf of the ATS Health Equality Committee \\ ${ }^{1}$ Department of Medicine, ${ }^{2}$ Department of Pediatrics, and ${ }^{3}$ Department of Bioengineering and Therapeutic Sciences and Department of \\ Medicine, University of California, San Francisco, San Francisco, California; and ${ }^{4}$ Department of Medicine, University of Illinois at \\ Chicago, Chicago, Illinois
}

\begin{abstract}
Health disparities are prevalent across diseases of the respiratory system, and are major sources of morbidity and mortality among disadvantaged populations in the United States. The American Thoracic Society (ATS) aims to reduce disparities that are both avoidable and unjust. In meeting this goal, the ATS is committed to creating the Lung Corps, a diverse group of senior, mid-level, and junior clinicians, trainees, researchers, and public health practitioners to help achieve health equality. This will be achieved through the following mechanisms: (1) increase awareness of health disparities; (2) empower health professionals with the knowledge and tools to address disparities; (3) shape
\end{abstract}

research agendas to focus on the root causes, to identify modifiable targets, and to promote innovative approaches to reduce disparities; and (4) develop and advocate for health-related policies and regulations that improve the respiratory health of the population. To ensure success, the Lung Corps will interact with other societies, agencies, and organizations to effect elimination of disparities in respiratory health. The ATS is committed to identifying and addressing health disparities to improve the overall health of individuals affected by respiratory diseases.

Keywords: health disparities; American Thoracic Society; respiratory tract diseases; Lung Corps; health policy

(Received in original form February 11, 2014; accepted in final form March 14, 2014)

*These authors contributed equally to this manuscript.

Supported in part by the National Institutes of Health (R01-ES015794, U19-Al077439, R01-HL088133, R01-HL078885, and R01-HL104608); National Institute on Minority Health and Health Disparities of the National Institutes of Health under award no. P60-MD006902; the Flight Attendant Medical Research Institute (FAMRI), the Sandler Foundation, the RWJF Amos Medical Faculty Development Award (to E.G.B.), and the American Asthma Foundation (to E.G.B.). The content is solely the responsibility of the authors and does not necessarily represent the official views of the National Institutes of Health.

Correspondence and requests for reprints should be addressed to Neeta Thakur, M.D., M.P.H., Department of Medicine, University of California, San Francisco, San Francisco, CA 94143. E-mail: Neeta.Thakur@ucsf.edu

Ann Am Thorac Soc Vol 11, No 4, pp 655-660, May 2014

Copyright (C) 2014 by the American Thoracic Society

DOI: 10.1513/AnnalsATS.201402-061AR

Internet address: www.atsjournals.org

Health disparities, defined as significant differences in health between populations, are prevalent in diseases of the respiratory system. Respiratory diseases (e.g., obstructive lung diseases, lung cancer, acute respiratory illnesses, and tuberculosis) are major sources of morbidity and mortality among disadvantaged populations in the United States. These health disparities have multiple determinants, including socioeconomic status, reduced health care access and access to quality health care providers, health literacy, cultural beliefs, individual choices, social and family situations, legal and structural constraints, and racial and ethnic discrimination. Moreover, many diseases of the respiratory system are linked in their causation and exacerbation to environmental exposures that disproportionately affect disadvantaged populations. For example, minority and socioeconomically disadvantaged children are disproportionately exposed to higher levels of air pollution (1-3) and are more likely to have serious asthma complications compared with whites $(4,5)$. The American Thoracic Society (ATS) aims to reduce those disparities that are both avoidable and unjust $(6,7)$. The ATS is developing the Lung Corps in response to its mission to reduce these disparities and achieve health equity. The mandate of this group will be to directly address disparities in pulmonary, critical care, and sleep medicine by promoting scientific inquiry and training, 
disseminating medical information and best practices, and monitoring and advocating for public respiratory health.

The Lung Corps brings together a diverse group of senior, mid-level, and junior members with diverse backgrounds (e.g., M.D., Ph.D., R.N., M.S., R.T., P.A.) and from the many assemblies within the ATS that are committed to reducing health disparities. This group is explicitly transdisciplinary, linking researchers with clinical expertise in pulmonary, critical care medicine, pediatrics, infectious disease, and public health with methodological experts in disparities, genetics, biology, epidemiology, biostatistics, behavioral and social sciences, health policy, political sciences, and communication sciences. It is critical to coordinate and integrate research between basic sciences, clinical medicine, behavioral science, and public health to obtain the greatest benefit when attempting to untangle the complexity of health disparities. This will lead to a better understanding of root causes of disparities, which will allow for expedited solutions to avoidable health disparities.

The Lung Corps consists of committed and collaborative transdisciplinary experts ready to increase stakeholder involvement to maximize elimination of respiratory health disparities. The Lung Corps will implement the following strategies to address health disparities in respiratory diseases (Figure 1):

- Increase awareness among health care professionals about respiratory health disparities and how to approach them in a multidisciplinary and collaborative manner that leads to effective health policies.

- Empower health care professionals to engage relevant communities and to find collaborative solutions. To that end, the Lung Corps will assist in the dissemination and creation of tools to be used by health professionals to work with and empower relevant communities to improve health outcomes.

- Shape research agendas at the National Institutes of Health, Agency for Healthcare Research and Quality, Veterans' Administration, Centers for Disease Control and Prevention, Patient-Centered Outcomes Research Initiative, and Congress and among ATS members that will contribute relevant evidence, promote research training on the topic, and provide venues for discussion of research on disparities. The research will focus on the origins of health disparities, including the social, behavioral, environmental, molecular, health policy, and other relevant influences, and the modifiable aspects of these disparities with the main goal of improving public health and outcomes for all patients.

- Develop and advocate for policies that will address the sources of health disparities. The Lung Corps will promote strategies based on models that have shown that reducing health disparities results in better economic as well as clinical outcomes.

\section{The ATS LUNG CORPS}

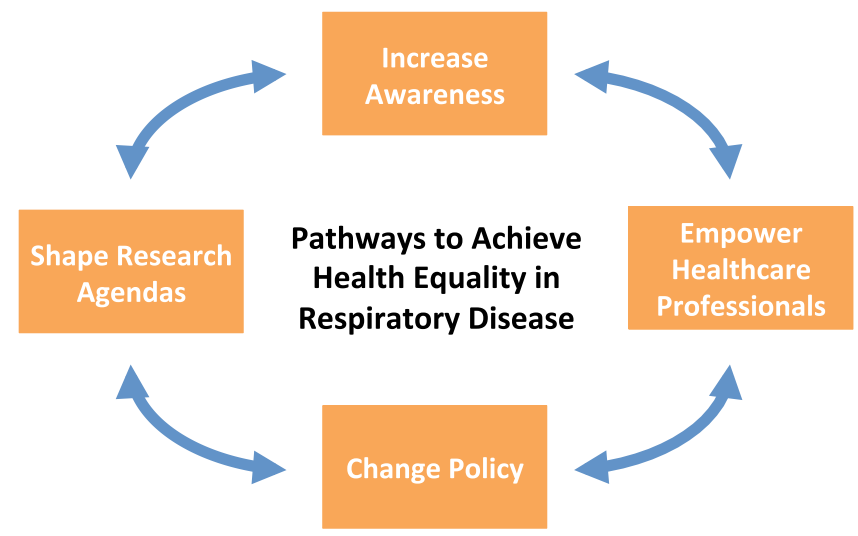

Figure 1. The American Thoracic Society's Lung Corps will implement the following mechanisms to achieve health equality in lung health: (1) increase awareness of health disparities; (2) empower health professionals with the knowledge and tools to address disparities; (3) shape research agendas to focus on the root cause, identify modifiable targets, and promote innovative approaches to reduced disparities; and (4) develop and advocate for health policies that improve the respiratory health of the population.

\section{Increase Awareness of Health Disparities}

\section{Overview of Health Disparities in Respiratory Diseases}

Social, behavioral, and environmental determinants of health are responsible for a larger portion of poor health outcomes than medical care quality and access (8-10). These social and environmental factors play an important role in the development of respiratory diseases as they shape healthrelated behaviors (e.g., tobacco smoking, treatment adherence, health care seeking) and modulate the effects of physiological processes (e.g., air pollution). In addition, these factors disproportionately affect poor, minority populations. African Americans and Latinos have greater than twice the odds of living in poverty compared with non-Hispanic whites (11). Low socioeconomic status is associated with high exposure to secondhand smoke $(12,13)$, poor housing quality $(14,15)$, increased exposure to air pollution $(16,17)$, increased exposure to violence $(18,19)$, poor nutritional status (20), decreased health care and medication access $(21,22)$, and lower adherence to treatment, each of which is an important predictor of poor respiratory health in children and adults $(13,14,18,21,23-27)$. Individuals with low socioeconomic status often have little control over changing their personal environment to reduce exposure to major risk factors for respiratory disease $(28,29)$. Compared with the highest socioeconomic status groups, individuals in the lowest groups are 14 times more likely to have respiratory diseases (6). African-American and Puerto Rican children have among the highest asthma prevalence and mortality rates in the United States (5). Latinos as a group experience an excess of asthmarelated symptoms, missed school days, and unplanned medical visits compared with whites $(30,31)$. These disparities are most pronounced among the very poor; for example, African-American children have an increased risk of asthma compared with white children of the same income level (32). These findings highlight the importance of environmental, social, and genetic factors in the development of health disparities. Similar findings have been observed in chronic obstructive pulmonary disease, lung cancer, acute illness, HIV-related lung disease, and tuberculosis 
(6, 26, 27, 33, 34). Understanding the complex interplay among the biological, behavioral, social, and environmental determinants of respiratory disease in disadvantaged populations is crucial for improving the overall health of the population.

\section{Strategies to Increase Visibility of the Problem of Health Disparities}

Reducing disparities in respiratory health based on race, ethnicity, socioeconomic status, and geography requires awareness and understanding of (1) the disparities themselves, (2) the groups most vulnerable to disparities, and (3) the factors that contribute to disparities and that are the most amenable to intervention. Thus, research and innovation are crucial to understanding, treating, and controlling respiratory diseases, generally, and for addressing health disparities, specifically. Novel and significant findings should be rapidly disseminated and translated to help facilitate improvements in clinical practice and patient care. Specific goals for dissemination include promoting new findings to (1) stimulate further investigation in different populations; (2) determine which disparities are predominantly responsible for poor health outcomes; and (3) identify which aspects of identified disparities are amenable to intervention and the time points that offer the most value for intervention. By increasing visibility of these health disparities, the ATS Lung Corps will help increase and strengthen available resources for identifying and addressing these disparities. Our target audience includes (1) researchers and clinicians interested in respiratory health, (2) medical and other health professional trainees, (3) public health practitioners, (4) elected officials and public policy makers, and (5) patient advocacy groups. At present, there are several avenues that exist to reach this diverse group, including publication of manuscripts of important findings and effective interventions; use of social media; websites of prominent organizations, including the ATS; and national and international health-related conferences. The use of social media offers a novel avenue to disseminate information to audiences outside of the ATS's usual partners and collaborators. In addition, social media have the potential to increase productive engagement with young investigators and trainees interested in improving health disparities.

The annual ATS International Conference offers a unique opportunity both to present innovative health disparity-related research and to build new collaborations with investigators who have shared interests as part of the Lung Corps. This year (2014), a key message from the leadership to all assemblies is addressing health disparities of respiratory health. This unified message will allow for rapid dissemination of new information, seminars focused on health disparities/health equities from a variety of disciplines, new opportunities for collaboration, and recognition of investigators and clinicians who have made significant contributions to this field. Other potential avenues include ATS-sponsored webinars and "how to" guides to disseminate innovative approaches/methods to addressing disparities.

\section{Empower Health Care Professionals}

Increasing the diversity of health care providers and researchers who are dedicated to respiratory health will lead to improvement in the understanding of health disparities, increased access to healthrelated services, and greater satisfaction among patients. However, there is an underrepresentation of racial and ethnic minorities in health care that is also reflected within the ATS. A survey of ATS members performed in 1999-2000 demonstrated that a low percentage of members identified as African American (1.5\%), Hispanic (3.9\%), Native American or Alaskan native (0.1\%), or Pacific Islander $(0.1 \%)$. Moreover, when program directors of adult and pediatric pulmonary and critical care fellowship programs were surveyed regarding the diversity of their trainee programs, the results again indicated remarkable underrepresentation of African Americans (4\%), Hispanics (8\%), Native Americans $(0.9 \%)$, or Pacific Islanders $(0 \%)$. This implies that minority pulmonary and critical care physicians and scientists will continue to be underrepresented in the future (our unpublished report). Correcting the imbalance in the numbers of underrepresented persons entering the health care field is important for reducing disparities in respiratory health.

The Lung Corps aims to increase recruitment of minority physicians into adult and pediatric pulmonary and critical care fellowships and to provide mechanisms to enhance the training and retention of these providers. The ATS provides links to resources that support training of minority members. These include a variety of programs from the National Institutes of Health, such as their Minority Biomedical Research Support Awards from the National Institute for General Medical Sciences, which reach undergraduate, graduate, and medical students. These programs also offer research supplements for underrepresented minorities, and additional funding to hire minority researchers at all levels. The ATS website also includes links to minority faculty development, minority access to research careers, faculty postdoctoral positions, and institutional programs for minorities, travel, graduate training (Ph.D.), and undergraduate training. These opportunities are available from the National Institutes of Health, Robert Wood Johnson (e.g., Harold Amos Medical Faculty Development Program), Ford Foundation, and other sources.

ATS has taken several steps to develop programs to educate health professionals, researchers, and policy makers to reduce disparities in respiratory health. One example is the development of the ATS Center for Patients and Families, which includes patient education materials in a variety of media formats and literacy levels for both common and rare respiratory diseases. In addition, this center hosts a portal for health care professionals with text and videos about patient-provider communication and landmark videos and editorials from the American Medical Association and the Agency for Healthcare Research and Quality on health literacy. The ATS Lung Corps will support the development, testing, and dissemination of tools targeting education, community involvement, and health literacy. Last, as a professional society, the ATS will aid in the development of clinical guidelines to influence how diseases are studied, diagnosed, and managed to reduce health disparities with the goal of achieving health equality. 


\section{Shape Research Agendas}

The etiology and consequences of health disparities are multifactorial and reflect a complex interaction of many components (Figure 2) (6); further research is needed to understand and address health disparities. The Lung Corps aims to influence Congress to shape the research agendas of the National Institutes of Health, Agency for Healthcare Research and Quality, Veterans Administration, Centers for Disease Control and Prevention, Patient-Centered Outcomes Research Initiative, and other funding agencies to move the focus to research targeting health disparities. Health equality will be a central principle for the ATS, with an intentional emphasis on health disparities in the development and implementation of all programs, policies, and funding decisions for research.

Research should focus on the origins of health disparities and on enhancing efforts to address them, with the main goal of improving outcomes for patients and public health. This includes examining the effects of health policy, social, behavioral, environmental, molecular, and genetic influences on health disparities. Research directed toward health disparities that need urgent correction or that is focused on interventions that build on existing infrastructure and are responsive to community needs will be given a priority. In addition, there will be an emphasis on research that translates basic and clinical discoveries into improved outcomes of health equality. This will require diverse transdisciplinary approaches to studying health disparities that include the basic sciences, clinical research, epidemiology, behavioral and social sciences, economics, and health services. The ATS journals will encourage publication of health disparities research from this diverse transdisciplinary group of investigators.

The ATS has had previous success in shaping research and training agendas to focus on global health with the Methods in Epidemiologic, Clinical and Operations Research (MECOR) program. This program provides training in research with the goal to improve global lung health through the development of local and regional lung disease research capacity $(35,36)$. A similar model can be applied to train clinicians and researchers in methods to examine health disparities in their own research. In

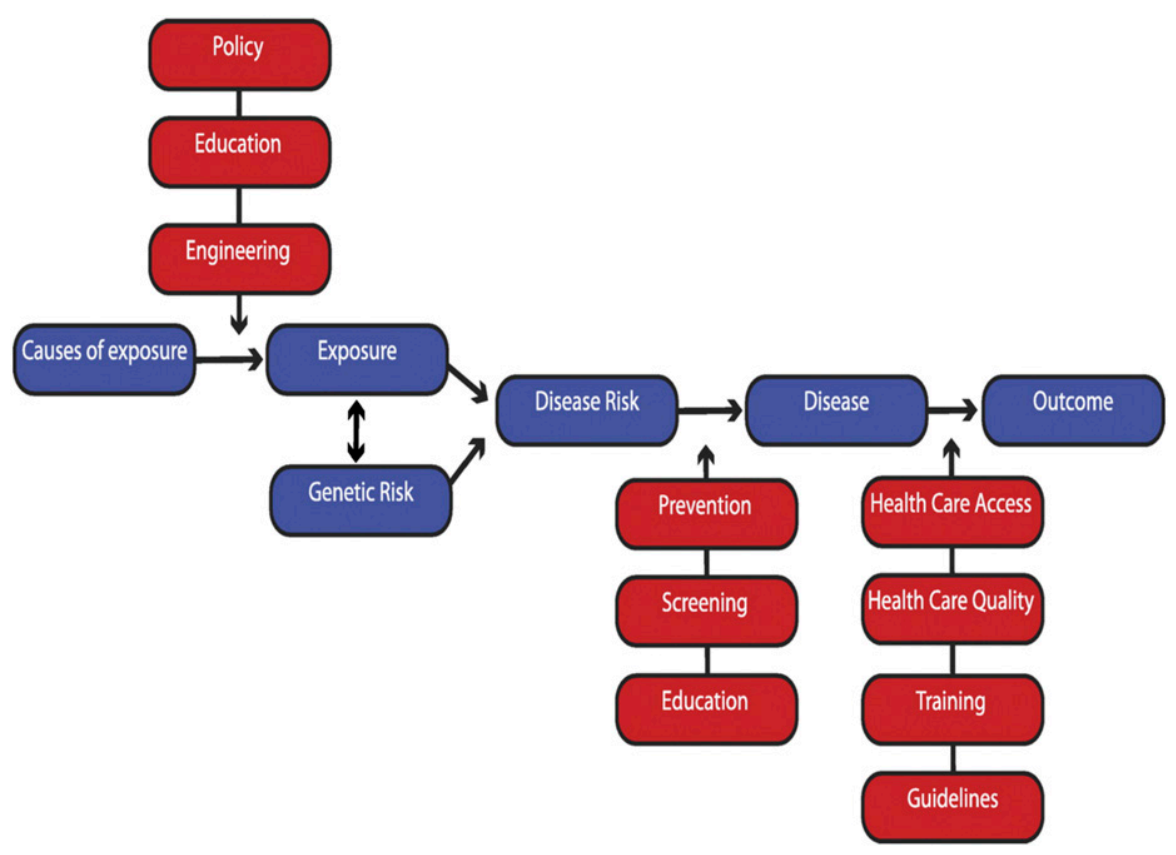

Figure 2. Illness results from an event occurring in or to a susceptible person. The event is usually an environmental exposure; being susceptible is affected by an individual's genetic makeup and the degree of exposure. Health disparities can result from either, and can be ameliorated by specific steps. The path to sickness is illustrated in the blue boxes. The interventions to ameliorate them are contained in the red boxes. Adapted by permission from Reference 6 .

addition, the ATS supports the development of research training and educational programs on health disparities for new and established investigators. The Lung Corps promotes a collaboration of researchers interested in health disparities.

Research on health disparities will not occur without providing funding and support for researchers. The Lung Corps will promote funding for health disparities research in every branch of the ATS. A steady expansion of federal funding for health disparities research is a critical priority. The Lung Corps will encourage a meeting of medical subspecialty societies with the White House Office of Management and Budget Staff to promote funding for health disparities on a national level.

\section{Develop and Advocate for Policies}

Our endeavor to further understand and improve health disparities cannot end with scientific investigation; the knowledge gained must be translated into policies. The Lung Corps is focused on developing and advocating for policies that both address the root causes of health disparities and are grounded in scientific knowledge. Research should be policy relevant and policies targeting health disparities should be evidence based.

There needs to be an enhanced diffusion of insight gained on health disparities research findings from researchers to policy makers. The Lung Corps will increase interaction between clinicians, researchers, advocates, and policy makers to develop a strategic plan for addressing health disparities that include both short-term and long-term thinking and planning. Ending health disparities in respiratory diseases needs to be a priority on all local, state, and national health agendas. The Lung Corps will encourage and promote increased advocacy of health equality in Washington, DC, such as including health disparities as a priority on ATS Hill Day. Another goal of the Lung Corps is to promote the expansion of current policies that promote equality such as greater health care access for all, reduction in air pollution, and promotion of tobacco control. Last, the Lung Corps will promote strategies informed by models that have shown that reducing health disparities 
results in better economic as well as clinical outcomes. This will include monitoring and advocating for effective public health strategies.

The ATS and its members have a successful track record of translating research into policy changes with tobacco control. ATS members were involved in the development of the Framework Convention on Tobacco Control with the World Health Organization. This widely endorsed public health treaty has been ratified by 176 countries, but not the United States. The ATS has partnered with more than 350 nongovernmental agencies under the Framework Convention Alliance to support implementation of the treaty. The ATS's experience and success with tobacco control can be translated to target health disparities. The Lung Corps will promote a transdisciplinary coalition of health disparities partners by providing leadership in the health disparities field and inspiring individuals, organizations, and other professional medical societies. This emphasis of the Lung Corps includes supporting the development of programs and the building of infrastructures to address health disparities. The Lung Corps will encourage the development of ATS health disparities meetings with other organizations and groups to disseminate information about policies and to encourage networking.

A call to action from the general public is needed to end health disparities. The Lung Corps will promote increased awareness about health disparities among the general population by collaborating with the ATS Public Advisory Roundtable on important public health equality issues. The ATS can influence professional behavior and norms of society through our journals, meetings, and websites. Media promotion of health disparities will be a priority to increase visibility of this critically important public health issue.

Progress in eliminating health disparities will not be made without changes to health policies at every level of society. Health policies will fail to improve health disparities if they are not deeply rooted in research and if the health sector chooses to act alone.

\section{Summary}

Health disparities in respiratory diseases negatively impact patients' health and our global community. Their etiology is multifactorial and complex but integral to understanding how to promote health equality. The ATS is committed to fostering increased awareness among health care professionals, government officials, and the general population of the impact of health disparities on respiratory diseases. The ATS must train and prepare health care professionals on how to address health disparities. Moreover, health disparities research needs to promoted, encouraged, and supported by the ATS. Most importantly, this research needs to be translated into effective interventions and health policies. The Lung Corps will be a transdisciplinary group of ATS members who are committed to reducing health disparities. We will track the progress of the ATS in reducing respiratory health disparities and achieving health equality. To ensure success, the Lung Corps will collaborate with other societies, agencies, and organizations to effect elimination of disparities in respiratory health. We are committed to finding solutions for health disparities and improving health for pulmonary patients worldwide.

Author disclosures are available with the text of this article at www.atsjournals.org.

Acknowledgment: The authors thank the leadership of the ATS for initiating the Health Equality Committee and for supporting the elimination of health disparities.

\section{References}

1 Mott $\mathrm{L}$. The disproportionate impact of environmental health threats on children of color. Environ Health Perspect 1995;103:33-35.

2 Metzger R, Delgado JL, Herrell R. Environmental health and Hispanic children. Environ Health Perspect 1995;103:25-32.

3 Miranda ML, Edwards SE, Keating MH, Paul CJ. Making the environmental justice grade: the relative burden of air pollution exposure in the United States. Int J Environ Res Public Health 2011; 8:1755-1771.

4 Leong AB, Ramsey CD, Celedón JC. The challenge of asthma in minority populations. Clin Rev Allergy Immunol 2012;43:156-183.

5 Akinbami LJ, Moorman JE, Bailey C, Zahran HS, King M, Johnson CA, Liu X. Trends in asthma prevalence, health care use, and mortality in the United States, 2001-2010. NCHS data brief 2012;94:1-8.

6 Schraufnagel DE, Blasi F, Kraft M, Gaga M, Finn PW, Rabe KF; ATS/ ERS Committee on Disparities in Respiratory Health. An official American Thoracic Society/European Respiratory Society policy statement: disparities in respiratory health. Am J Respir Crit Care Med 2013;188:865-871.

7 Braveman P. Health disparities and health equity: concepts and measurement. Annu Rev Public Health 2006;27:167-194.

8 Adler NE, Newman K. Socioeconomic disparities in health: pathways and policies. Health Aff (Millwood) 2002;21:60-76.

9 McGinnis JM, Foege WH. Actual causes of death in the United States. JAMA 1993;270:2207-2212.

10 Canino G, McQuaid EL, Rand CS. Addressing asthma health disparities: a multilevel challenge. J Allergy Clin Immunol 2009;123: 1209-1217, quiz 1218-1219.
11 Elmelech Y, Lu HH. Race, ethnicity, and the gender poverty gap. Soc Sci Res 2004;33:158-182.

12 Singh GK, Siahpush M, Kogan MD. Disparities in children's exposure to environmental tobacco smoke in the United States, 2007. Pediatrics 2010;126:4-13.

13 Oh SS, Tcheurekdjian H, Roth LA, Nguyen EA, Sen S, Galanter JM, Davis A, Farber HJ, Gilliland FD, Kumar R, et al. Effect of secondhand smoke on asthma control among black and Latino children. J Allergy Clin Immunol 2012;129:1478-1483.e7.

14 Holt EW, Theall KP, Rabito FA. Individual, housing, and neighborhood correlates of asthma among young urban children. $J$ Urban Health 2013;90:116-129.

15 Evans GW, Kantrowitz E. Socioeconomic status and health: the potential role of environmental risk exposure. Annu Rev Public Health 2002;23:303-331.

16 Nishimura KK, Galanter JM, Roth LA, Oh SS, Thakur N, Nguyen EA, Thyne S, Farber HJ, Serebrisky D, Kumar R, et al. Early-life air pollution and asthma risk in minority children: the GALA II and SAGE II Studies. Am J Respir Crit Care Med 2013;188: 309-318.

17 Forastiere F, Stafoggia M, Tasco C, Picciotto S, Agabiti N, Cesaroni G, Perucci CA. Socioeconomic status, particulate air pollution, and daily mortality: differential exposure or differential susceptibility. $A m$ $J$ Ind Med 2007;50:208-216.

18 Wright RJ, Mitchell H, Visness CM, Cohen S, Stout J, Evans R, Gold DR. Community violence and asthma morbidity: the Inner-City Asthma Study. Am J Public Health 2004;94:625-632.

19 Burke NJ, Hellman JL, Scott BG, Weems CF, Carrion VG. The impact of adverse childhood experiences on an urban pediatric population. Child Abuse Negl 2011;35:408-413. 
20 Wang MC, Kim S, Gonzalez AA, MacLeod KE, Winkleby MA. Socioeconomic and food-related physical characteristics of the neighbourhood environment are associated with body mass index. J Epidemiol Community Health 2007;61:491-498.

21 Cabana MD, Lara M, Shannon J. Racial and ethnic disparities in the quality of asthma care. Chest 2007;132(5, Suppl):810S-817S.

22 Weissman JS, Stern R, Fielding SL, Epstein AM. Delayed access to health care: risk factors, reasons, and consequences. Ann Intern Med 1991;114:325-331.

23 Horton NJ, Roberts K, Ryan L, Suglia SF, Wright RJ. A maximum likelihood latent variable regression model for multiple informants. Stat Med 2008;27:4992-5004.

24 Ortega AN, Gergen PJ, Paltiel AD, Bauchner H, Belanger KD, Leaderer BP. Impact of site of care, race, and Hispanic ethnicity on medication use for childhood asthma. Pediatrics 2002;109:E1.

25 Northridge J, Ramirez OF, Stingone JA, Claudio L. The role of housing type and housing quality in urban children with asthma. J Urban Health 2010; 87: 211-224.

26 Eisner MD, Blanc PD, Omachi TA, Yelin EH, Sidney S, Katz PP, Ackerson LM, Sanchez G, Tolstykh I, Iribarren C. Socioeconomic status, race and COPD health outcomes. $J$ Epidemiol Community Health 2011;65:26-34.

27 Mannino DM, Buist AS. Global burden of COPD: risk factors, prevalence, and future trends. Lancet 2007;370:765-773.

28 Isaacs SL, Schroeder SA. Class-the ignored determinant of the nation's health. N Engl J Med 2004;351:1137-1142.
29 Adler NE, Snibbe AC. The role of psychosocial processes in explaining the gradient between socioeconomic status and health. Curr Dir Psychol Sci 2003;12:119-123.

30 Akinbami L; Centers for Disease Control and Prevention; Nationa Center for Health Statistics. The state of childhood asthma, United States, 1980-2005. Adv Data 2006;381:1-24.

31 Lieu TA, Lozano P, Finkelstein JA, Chi FW, Jensvold NG, Capra AM, Quesenberry CP, Selby JV, Farber HJ. Racial/ethnic variation in asthma status and management practices among children in managed Medicaid. Pediatrics 2002;109:857-865.

32 Smith LA, Hatcher-Ross JL, Wertheimer R, Kahn RS. Rethinking race/ ethnicity, income, and childhood asthma: racial/ethnic disparities concentrated among the very poor. Public Health Rep 2005;120: 109-116.

33 Ellison-Loschmann L, Sunyer J, Plana E, Pearce N, Zock JP, Jarvis D, Janson C, Antó JM, Kogevinas M; European Community Respiratory Health Survey. Socioeconomic status, asthma and chronic bronchitis in a large community-based study. Eur Respir $J$ 2007;29:897-905.

34 Lönnroth K, Jaramillo E, Williams BG, Dye C, Raviglione M. Drivers of tuberculosis epidemics: the role of risk factors and social determinants. Soc Sci Med 2009;68:2240-2246.

35 Hopewell PC. We help the world breathe. Ann Am Thorac Soc 2013; 10:357-358.

36 Parry V. The American Thoracic Society Methods in Epidemiologic, Clinical, and Operations Research program: research capacity building in action. Ann Am Thorac Soc 2013;10:383-385. 